\title{
The effect of heat treatments on pure and potassium doped drawn tungsten wires: Part I - Microstructural characterization
}

\author{
Vladica Nikolić ${ }^{a}$, Johann Riesch ${ }^{b}$, Reinhard Pippan ${ }^{a}$ \\ a Erich Schmid Institute of Materials Science of the Austrian Academy of Sciences, Leoben, Austria \\ b Max-Planck-Institut für Plasmaphysik, 85748 Garching, Germany
}

\section{Keywords}

Tungsten wires, potassium doping, microstructure, annealing, recrystallization, EBSD analyses

\begin{abstract}
Advanced tungsten fibre-reinforced composites $\left(\mathrm{W}_{\mathrm{f}} / \mathrm{W}\right)$, showing pseudo ductile behaviour even at room temperature, are a promising option for future fusion reactors as the intrinsic brittleness of tungsten can be mitigated effectively. The drawn tungsten wires used as reinforcements are the key component of the composites, thus their mechanical properties and thermal stability define the allowed operation / fabrication temperature of the composite material itself. In this work, a comprehensive characterization of the pure and potassium doped tungsten wires was performed, focusing on the influence of various heat treatments on different microstructural features (nature of grain boundaries, grain shape and size, texture analyses) and mechanical properties. Annealing in the temperature range from 900 $1600^{\circ} \mathrm{C}$ enables the investigation of the microstructural stability of the two materials and arising annealing phenomena - recovery, recrystallization and grain growth. The results demonstrate that the pure tungsten recrystallizes fully in the temperature range 1300$1500^{\circ} \mathrm{C}$ accompanied with tremendous coarsening and a complete loss of the initial fibrous, elongated grain structure. In contrast to this, potassium doped wire shows superior high temperature properties, where performed heat treatments cause only milder microstructural changes, consequently suppressing recrystallization and grain growth to temperatures well above the investigated ones. Furthermore, hardness measurements and observed softening complement the discussion of the grain morphology evolution.
\end{abstract}




\section{Introduction}

The realization of commercial fusion energy systems is closely related to the development of the advanced materials capable of sustaining the harsh and challenging environment of a reactor device. This so called plasma facing components (PFC) are exposed to enormous particle fluxes, which impose extreme heat loads on the materials in use [1,2]. Tungsten (W) stands out as the most promising candidate for the first wall and divertor material $[3,4]$ due to the highest melting point of all metals (thus allowing operation at elevated temperatures), good thermal conductivity, low tritium retention and low erosion [5]. However, as other bcc metals, tungsten features an intrinsic brittleness below the ductile-to-brittle transition temperature, which is rather high, being typically around $200-300^{\circ} \mathrm{C}$ for a standard bulk tungsten and moreover increased upon annealing [6,7]. Additional challenges associated with the use of $\mathrm{W}$ are further operational embrittlement caused by neutron irradiation [8] and/or recrystallization by overheating $[9,10]$. Thus, a successful design of the next generation of fusion reactors will greatly depend on the availability of the novel options of the tungsten based materials.

Tungsten fiber-reinforced composites $\left(\mathrm{W}_{\mathrm{f}} / \mathrm{W}\right)$ are extensively investigated as a potential material for advanced plasma facing components [11]. This composite structure is obtained by embedding commercially available drawn tungsten wires in a tungsten matrix which is produced either by powder metallurgy [12] or by a chemical deposition process [13]. The advantage of $\mathrm{W}_{\mathrm{f}} \mathrm{W}$ is in its pseudo ductile behavior and thereby increased toughness as a consequence of extrinsic toughening mechanism such as crack bridging by intact fibers, fiber pull-out, crack deflection and ductile deformation of fibers [14]. In such a way, the brittleness problem of $\mathrm{W}$ can be mitigated, making $\mathrm{W}_{\mathrm{f}} \mathrm{W}$ composite a feasible PFC alternative. The drawn tungsten wires used as reinforcements are the key structural component of $W_{f} / W$ composite, which sets the requirement of investigating their mechanical and microstructural properties.

The research on $\mathrm{W}$ wires was rather extensive in the past century as this type of material has been used in the light bulb industry as a filament element [15]. The initial efforts were directed towards improving the production and processing routes while mainly using pure tungsten wire. However, embrittlement of pure tungsten as a result of recrystallization, grain growth and thermal fatigue arose as the main issue, which directly influenced lifetime performance of the lamps. The big breakthrough, which determined the course of wire research in the next few decades, was the discovery of the advantageous effect of the doping of tungsten by potassium (K). $\mathrm{K}$ bubbles strengthen the grain boundaries by acting as pinning sites and in such way 
suppress the grain growth to higher temperatures. Thus, the initial advantageous, elongated grain structure can be preserved for a longer operational time. An improved potassium bubble strengthened non-sag tungsten wire was of great importance for the incandescent lamps due to its increased creep resistance at very high temperatures and excellent coiling properties at room temperature [16]. Following years were mostly dedicated to the investigation of topics regarding the potassium bubbles such as their formation and evolution during production [17-19], size modifications during operation [20], mechanisms of reshaping the bubbles during the deformation $[21,22]$, just to name a few.

The potential application of tungsten based composites as structural components for a fusion reactor increased the interest in studying $W$ wires with respect to mechanical properties and recently set off series of investigations. Both, pure and K-doped tungsten wires show exceptional ductility [23] and significant strength (due to the Hall-Petch effect) [24] at room temperature, properties important for facilitating toughening mechanisms of $\mathrm{W}_{\mathrm{f}} / \mathrm{W}$ through the crack bridging effect as well as the fiber deformation effect [25]. Furthermore, studies regarding the mechanical response and plastic deformation at elevated temperatures showed that the wire can keep its valuable properties [26,27]. Additionally, some investigations dealt with the question of the effect of annealing on tensile properties of pure [28] and potassium doped tungsten wire [29], interconnecting in such a way general microscopic features to different material responses occurring in the experiment.

Despite a rather wide-ranging body of research on tungsten wires, there are still open questions where a deeper microscopic understanding of the main, important properties is needed. In this context of using tungsten wires as a reinforcement material, performing fracture toughness experiments and investigating the underlying mechanisms that control the fracture process is of great importance. This holds true for the as-fabricated condition as well as for different states after annealing. The evolution of the different microstructural features as a result of annealing is very important as it is strongly related to the macroscopic materials response and in particular to the fracture behaviour.

The purpose of this work is to perform a systematic study on the effect of heat treatments in the broad range of annealing temperatures and investigate how microstructural and fracture properties develop upon annealing, with the special focus on the relationship between the investigated features. The study is divided into two parts. Here, in the first contribution, a comparison of the microstructural evolution is made between pure and potassium doped tungsten wires; hence, addressing the question of recrystallization phenomena and preservation of the grain structure by addition of doping elements. The use of advanced microscopy tools allows the 
detailed analyses of the evolution of different aspects of the microstructure (nature of grain boundaries, grain shape and size, texture) enabling the assessment of the different stages of occurring annealing phenomena. The second paper concentrates on the fracture toughness assessment and investigates embrittlement by annealing.

\section{Materials and experimental methods}

The materials investigated within this study are drawn pure and potassium doped (K-W, 60ppm) tungsten wires, commercially available and provided by the OSRAM $\mathrm{GmbH}$, Schwabmünchen. The standard fabrication of a tungsten based material is via the powder metallurgical route by sintering and swaging; subsequent drawing process enables obtaining the final, desired diameter of the wire. The nominal diameter of the investigated material for both types was $150 \mu \mathrm{m}$. Besides the asreceived wires, series of heat treated samples were produced from both materials. In order to thoroughly study the influence of annealing on the microstructure, heat treatments were conducted at following temperatures: $900^{\circ} \mathrm{C}, 1100^{\circ} \mathrm{C}, 1200^{\circ} \mathrm{C}$, $1300^{\circ} \mathrm{C}, 1400^{\circ} \mathrm{C}, 1500^{\circ} \mathrm{C}$ and $1600^{\circ} \mathrm{C}$. In each case, the holding time was 1 hour with subsequent cooling in furnace until room temperature. The oxidation was avoided by annealing in a tungsten based vacuum furnace (Leybold Heraeus PD 1000 ) at a pressure $<10^{-5} \mathrm{mbar}$. To exclude the influence of the composition, all the samples were cut from the same two spools of pure and K-doped tungsten wires, respectively; therefore, each having the same chemical composition and identical production process.

The preparation of samples suitable for further analyses was conducted by embedding the wire pieces in hard resin, followed by standard polishing steps resulting in the necessary smooth surfaces. For each material and annealing condition, samples were prepared in two principal viewing directions: longitudinal section (plane parallel to the drawing axis) and cross section (plane perpendicular to the drawing axis), as shown in the schematic drawing in Figure 1. The investigation of the microstructure was performed in a Zeiss Leo 1525 field-emissiongun scanning electron microscope (SEM) with an electron backscatter diffraction (EBSD) detector. The analysis was done using an acceleration voltage of $20 \mathrm{kV}$ and approximately $10 \mathrm{nA}$ probe current. For each kind of wire in both longitudinal and cross sections, an area of $25 \times 25 \mu \mathrm{m}^{2}$ was acquired with a step size of $100 \mathrm{~nm}$. Orientation Imaging Microscopy (OIM) software was used to evaluate the obtained EBSD scans. Post-processing was carried out by removing points with a confidence index lower than 0.1 . The evaluation of the acquired orientation maps allows the 
identification of the grain size distribution, qualitative description of the grain shape and studying the nature of the grain boundaries. Misorientations between $5^{\circ}-15^{\circ}$ are considered as low-angle grain boundaries (LAGB) and high-angle grain boundaries (HAGB) are defined for misorientations between $15^{\circ}$ and $65^{\circ}$. Pole figures, determined from the orientation information of the EBSD scans, enable studying the evolution of the texture.

To give the first impression of a correlation between the microstructure and mechanical properties Vickers hardness measurements were performed for both wires in the as-received and all annealed states. A load of $500 \mathrm{~g}$ was applied $(4.5 \mathrm{~N}$, HV0.5), with a dwell time of $15 \mathrm{~s}$. With these conditions, microhardness was measured in the central area of the longitudinal sections of the wire and for each sample 12 indentations were made within a distance of about $500 \mu \mathrm{m}$. The reported hardness values are statistical averages, with the indicated error bars being the standard deviation of the average values.

\section{3. $\underline{\text { Results }}$}

\subsection{Microstructural analyses}

The first impression of the deformed microstructure of the as-received wire can be seen from the backscatter electron (BSE) images, where the observed contrast of the image is related to different crystallographic orientations. The initial appearance of both materials is very similar; therefore, to avoid repetition, only the example of the doped tungsten wire in the longitudinal section (Figure 1a) and cross section (Figure $1 b$ ) is given. As a direct consequence of the drawing process of the wire, a unique microstructure is obtained consisting of extremely elongated grains along the drawing direction. Perpendicular to the drawing axis, uniformly distributed grains have significantly smaller dimensions. The grains are not equiaxed but rather twisted forming a characteristic curled structure. The influence of annealing, investigated through a systematic microstructural characterization comprising identification of changes of the grain shape and size, analyses of the grain boundaries and evolution of the developed texture, will be addresses in the following chapters. 


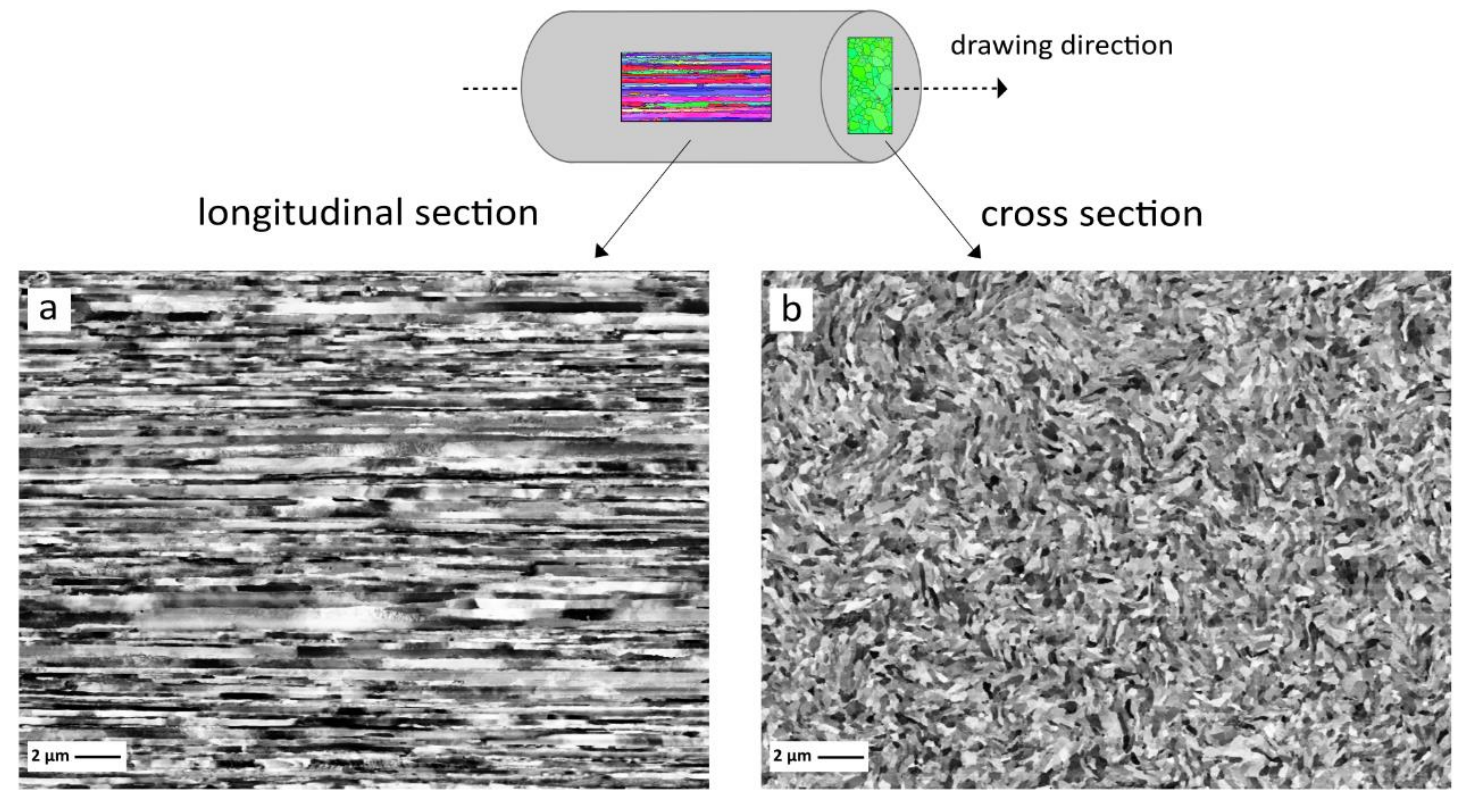

Figure 1. Scanning electron micrographs of the as-received potassium doped tungsten wire in the BSE mode taken in the central area across a) longitudinal section and b) cross-section. The schematic drawing on the top shows the principle direction of deformation, as well as the position of the typical scanning areas in respect to the drawing direction.

\subsubsection{Grain size and shape}

The effect of different heat treatments on the microstructural stability was studied through series of EBSD orientation maps by making a comparison between data acquired in the central region of the cross sections (Figure 2) and longitudinal sections (Figure 3 ) of pure and potassium doped wires. Grains are identified as areas with a continuous orientation, while the low-angle grain boundaries (LAGB, misorientation of $5^{\circ}-15^{\circ}$ ) and the high-angle grain boundaries (HAGB, misorientation of $\left.15^{\circ}-65^{\circ}\right)$ are distinguished in the orientation maps by red and black lines, respectively. Cross sectional scans of the as-received wire reveal a microstructure of uniformly distributed fine grains and in the case of both pure and potassium doped tungsten, similar appearance can be seen. With an increase in annealing temperature substantial microstructural modifications are observed for the pure $\mathrm{W}$ (Figure 2a and Figure 3a); continuous increase of the grain size is accompanied by the disappearance of curling structures and more equiaxed grain shape. Heat treatment at the highest temperature of $1600^{\circ} \mathrm{C}$ leads to tremendous grain growth when compared to the as-received state of the material. In contrast to these observations, K-W wires show only a mild increase in grain size and the 
microstructure remains rather stable over the entire temperature range (Figure 2b and Figure $3 \mathrm{~b}$ ). The noticeable uniformity of the grain colour in all the scans is an indication of a very pronounced and stable texture of the wires; however, this topic will be treated with greater detail in the chapter 3.1.3. The orientation maps acquired across the longitudinal sections reveal that both materials in the as-received condition have long, thin grains elongated in the drawing direction, with the shortest grain lengths in radial direction of the wire. As seen in Figure 3a, the characteristic elongated microstructure of the pure $\mathrm{W}$ wire is severely influence by heat treatments experiencing alternations in grain size (in both directions of the scan) already at lower temperatures of annealing. The significant coarsening eventually leads to the complete loss of fibrous appearance of the grains, where the microstructure of the final state consists of large, globular $\mu \mathrm{m}$ sized grains. Thermal stability of the Kdoped wire can be observed in Figure $3 \mathrm{~b}$, where regardless of some mild growth in the size of the grains, the overall elongated microstructure is preserved even for the highest annealing temperatures.

From the orientation maps obtained by EBSD, the qualitative analysis of the grain size as a function of annealing temperature is performed. In Figure 4a, the results extracted from the cross sectional scans can be seen, where the evolution of the area weighted grain diameter is compared for pure and $\mathrm{K}$-doped $\mathrm{W}$ wire. The microstructural stability of $\mathrm{K}-\mathrm{W}$ wire is clearly seen as the grain size increases only slightly over the entire range of annealing temperatures, going from $0.57 \mu \mathrm{m}$ in the as-received state to the $0.73 \mu \mathrm{m}$ for the $1600^{\circ} \mathrm{C}$ treated sample. However, the heat treatments considerably affect the pure $\mathrm{W}$ wire through a tremendous grain coarsening with an average grain diameter changing from $0.47 \mu \mathrm{m}$ (as-received state) to the value of $5.53 \mu \mathrm{m}\left(1600^{\circ} \mathrm{C} / 1 \mathrm{~h}\right)$. By employing the line intersect length method in both vertical and horizontal orientation of the longitudinal orientation maps, information regarding length and width of the elongated grains can be obtained (Figure $4 \mathrm{~b}$ and $4 \mathrm{c}$ ). Similar trends of the grain coarsening with an increase of annealing temperature can be observed for pure $\mathrm{W}$ wire. Furthermore, the aspect ratio close to 1 is in the agreement with the complete loss of elongated grain shape. $\mathrm{K}$-doped wire experiences significantly milder variations in grain size, with an increase being more pronounced for the length of the elongated grains. Nevertheless, when compared to pure wire, an overall stability of the microstructure can be observed with relatively small aspect ratio remaining rather constant. 


\section{a) pure $\mathbf{W}$}
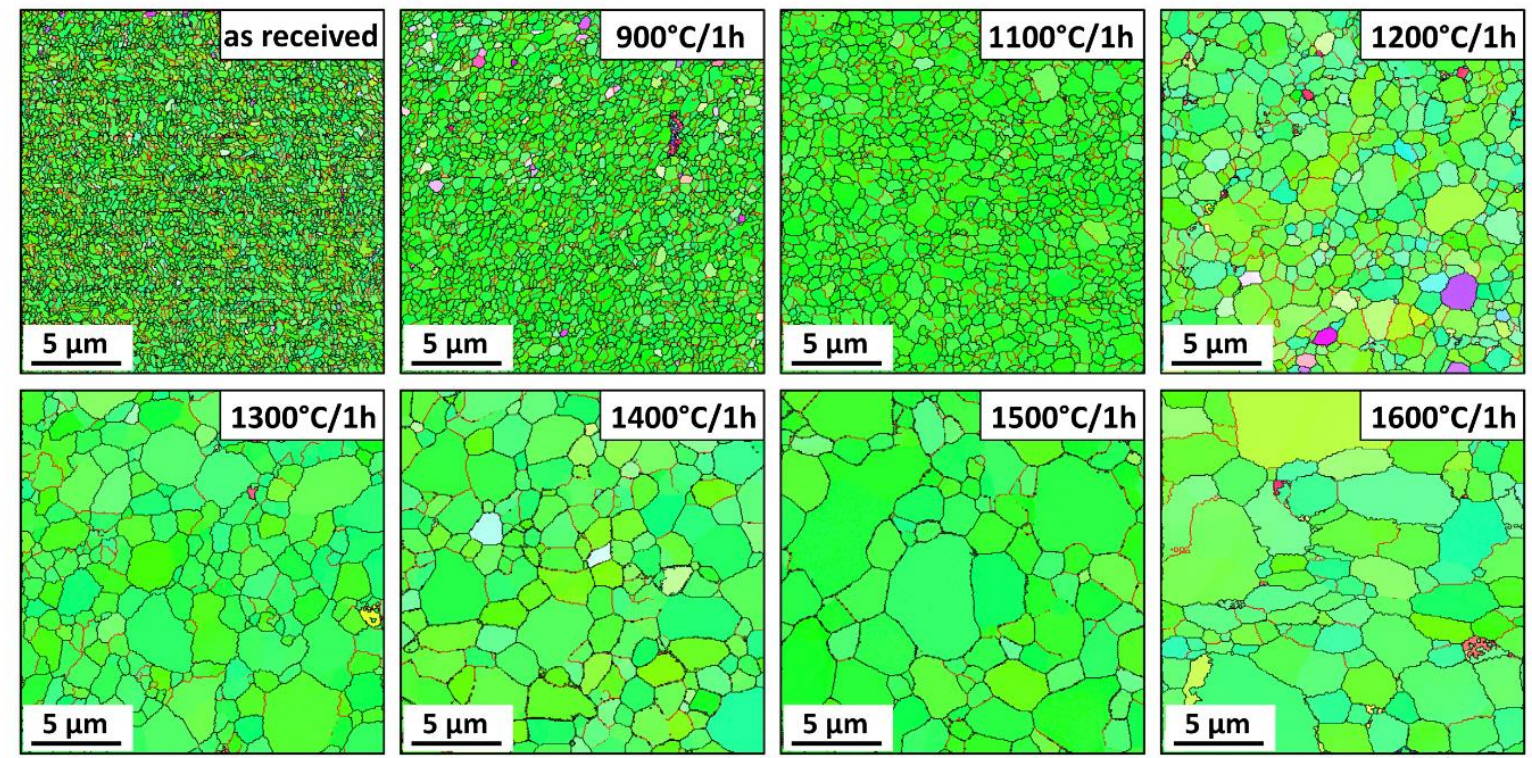

b) $\mathrm{K}$ doped $\mathrm{W}$
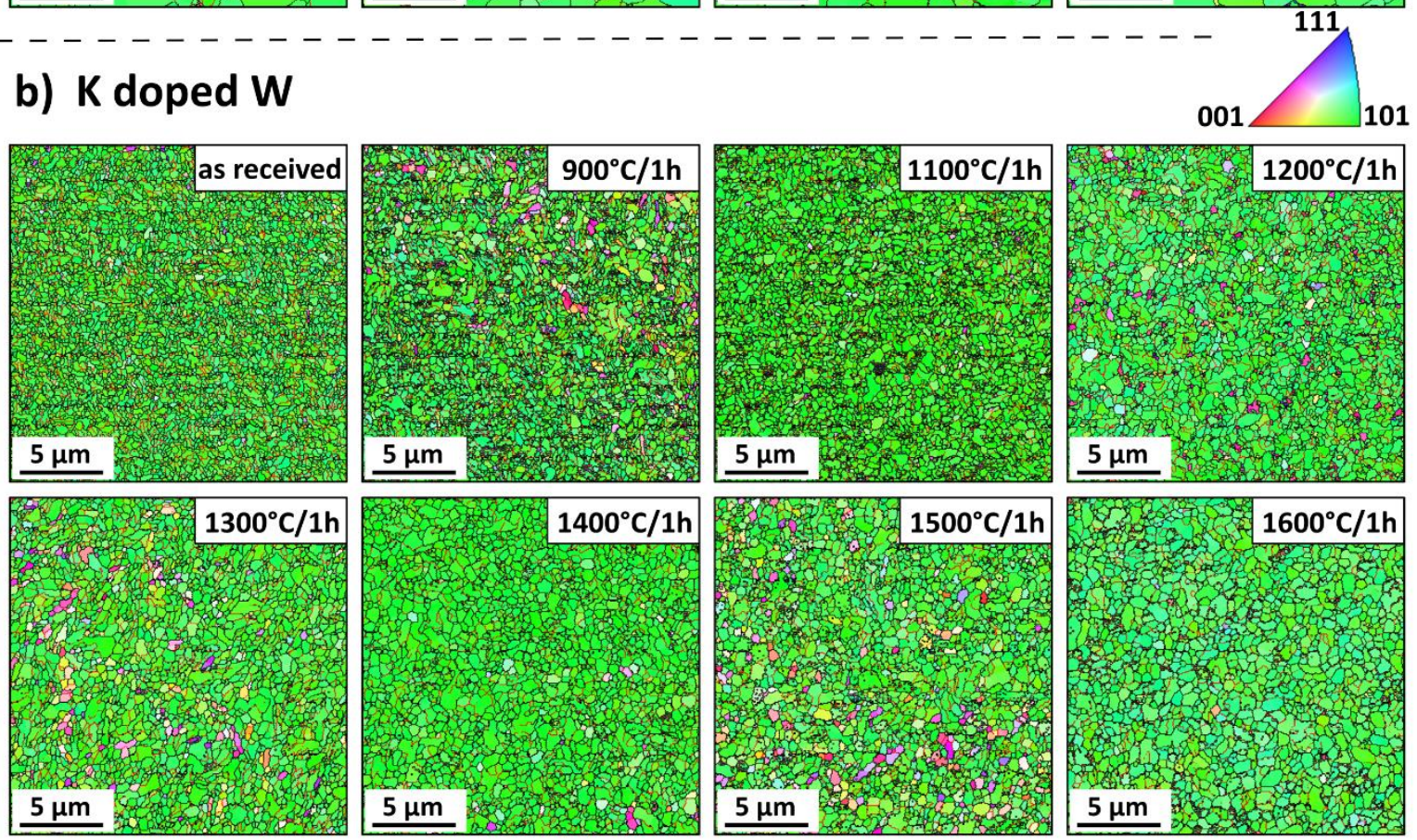

Figure 2. EBSD orientation maps of the cross sections of a) pure tungsten and b) potassium doped tungsten wires. The evolution of the microstructure and thermal stability are investigated in respect to different annealing treatments, performed in vacuum for $1 \mathrm{~h}$. Color coded unit triangle is given as well, representing $\langle 100\rangle,\langle 110\rangle$ and $\langle 111\rangle$ crystallographic directions perpendicular to the sample surface. All of the scans were taken with the same magnification. 


\section{a) pure W}
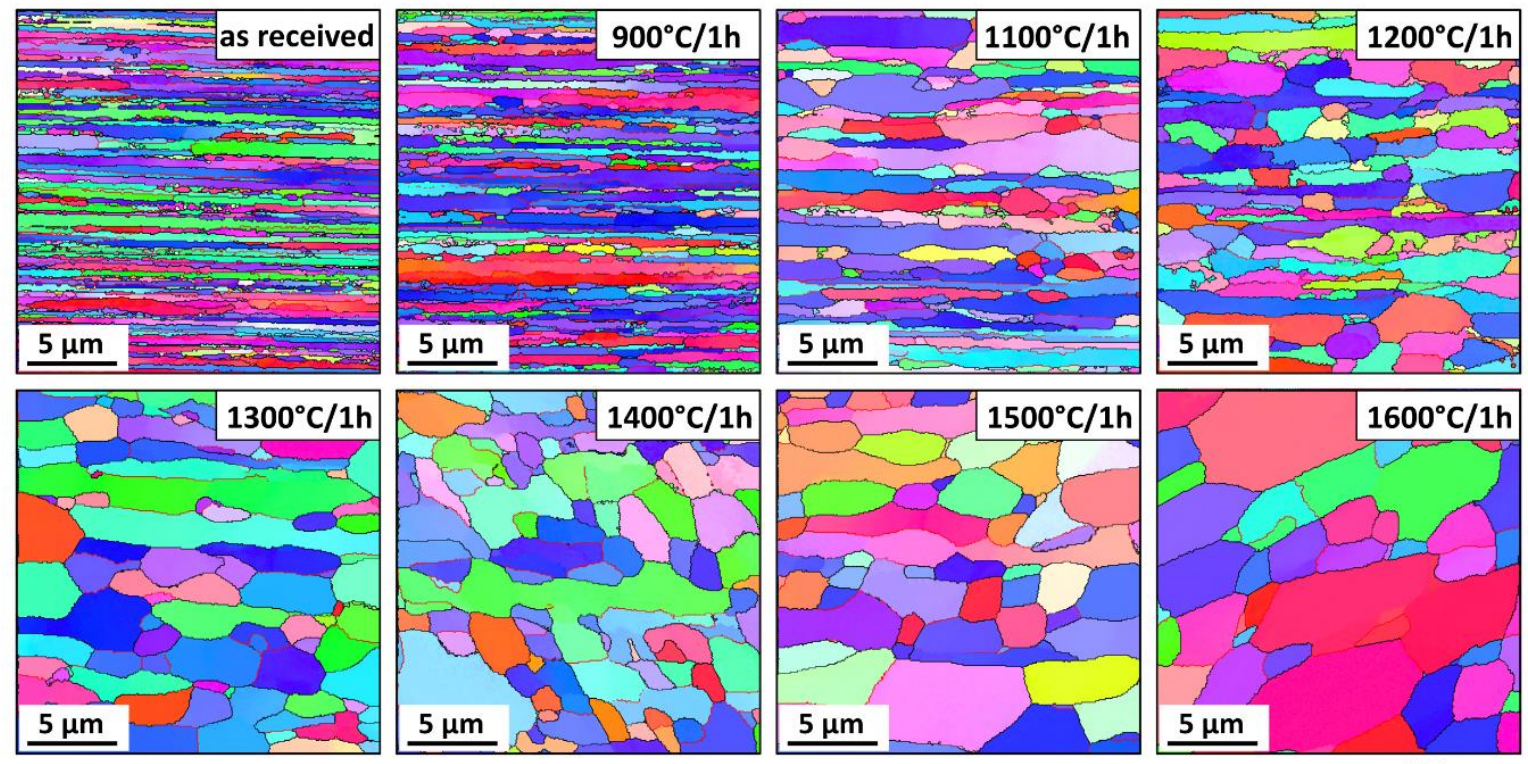

b) $\mathrm{K}$ doped $\mathrm{W}$
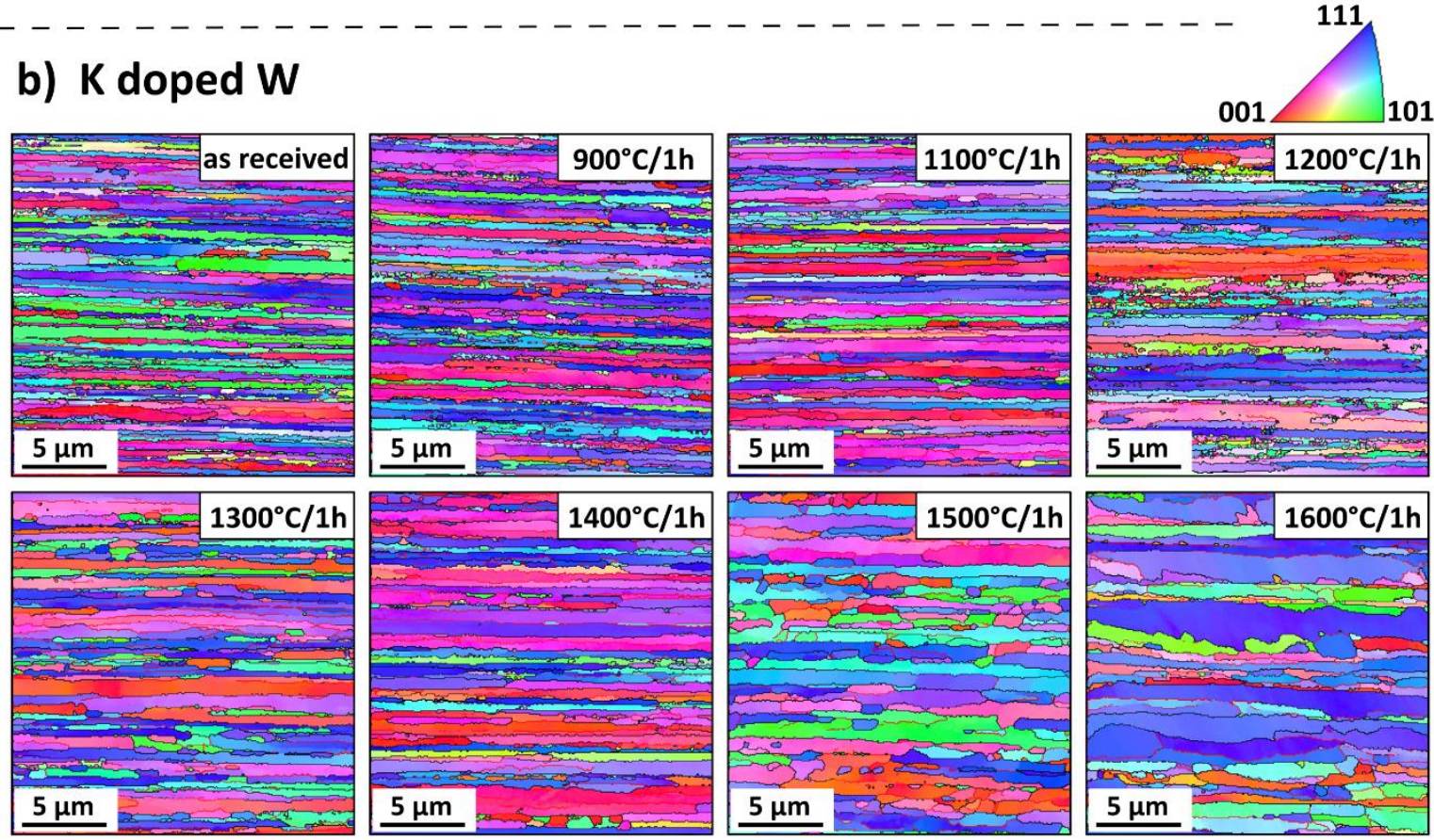

Figure 3. EBSD orientation maps of the longitudinal section of a) pure tungsten and b) potassium doped tungsten wires. The evolution of the microstructure and thermal stability are investigated in respect to different annealing treatments, performed in vacuum for $1 \mathrm{~h}$. Color coded unit triangle is given as well, representing $\langle 100\rangle,\langle 110>$ and $<111>$ crystallographic directions perpendicular to the sample surface. All of the scans were taken with the same magnification. 
a)

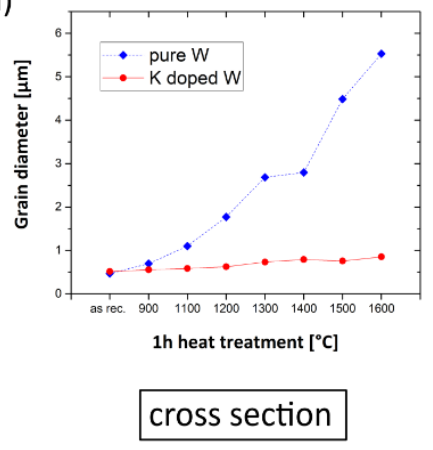

b)

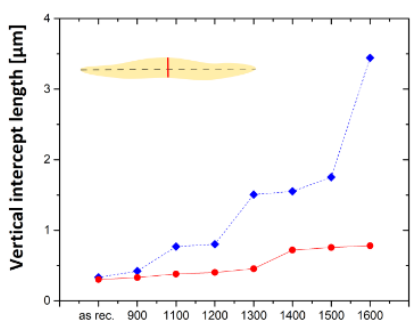

1h heat treatment $\left[{ }^{\circ} \mathrm{C}\right]$ c)

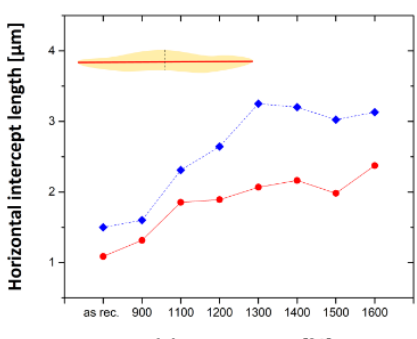

1h heat treatment $\left[{ }^{\circ} \mathrm{C}\right]$

longitudinal section

Figure 4. Evolution of the grain dimensions as a function of different annealing conditions, derived by a) area weighted grain diameters from the cross sectional EBSD maps, b) the line intersect method in the vertical direction of the longitudinal sections of the EBSD maps and c) the line intersect method in the horizontal direction of the longitudinal sections of the EBSD maps.

\subsubsection{The nature of grain boundaries}

The type of grain boundary is defined through misorientation angle between neighbouring grains and as already outlined, the low-angle grain boundaries (LAGB, $5^{\circ}-15^{\circ}$ ) and the high-angle grain boundaries (HAGB, $15^{\circ}-65^{\circ}$ ) are identified in the orientation maps in Figures 2 and 3 as red and black lines, respectively. In order to make these features more distinguishable from the underlying orientation maps, examplary grain boundary maps are given for pure tungsten in the as-received and $1600^{\circ} \mathrm{C} / 1 \mathrm{~h}$ conditions in both directions of the scanning area (Figure 5a). Furthermore, due to the importance of grain boundaries for the dislocation motion and related annealing phenomena, the misorientation angles were analysed by their frequency from which the information regarding the total GB length, as well as the individual contributions of LAGB and HAGB can be acquired. Analyses of the total amount of GB per scanning area in respect to different heat treatments are performed from the cross sectional (Figure $5 b$ ) as well as longitudinal orientation maps (Figure $5 \mathrm{c}$ ), where fractions of low-angle and high-angle grain boundaries are also shown. Furthermore, a comparison is made between the results of pure and Kdoped tungsten wires. 


\section{a) GB maps}
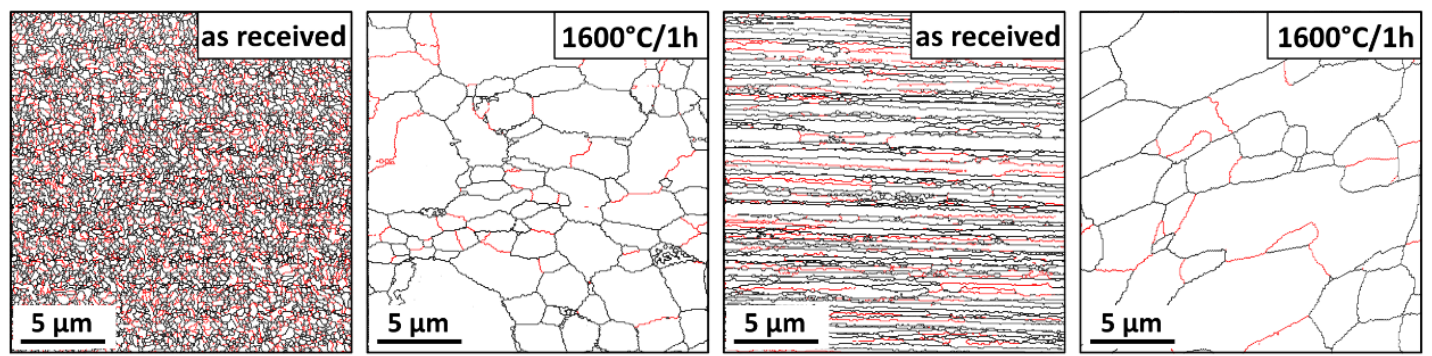

cross section

longitudinal section

\section{b) Total GB length per scanning area - cross section}
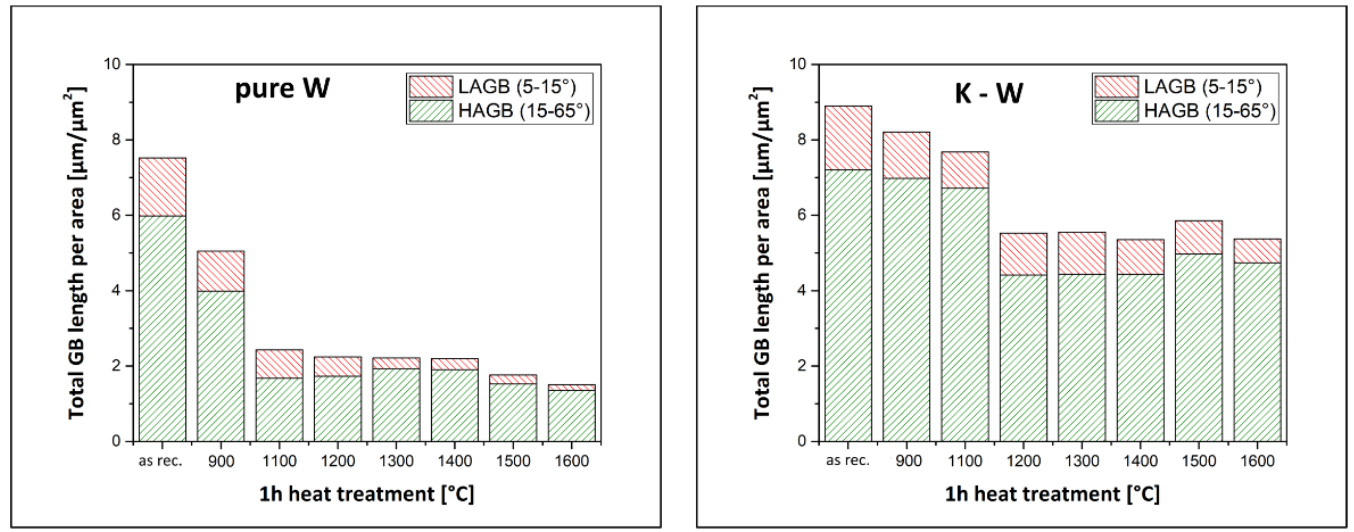

\section{c) Total GB length per scanning area - longitudinal section}
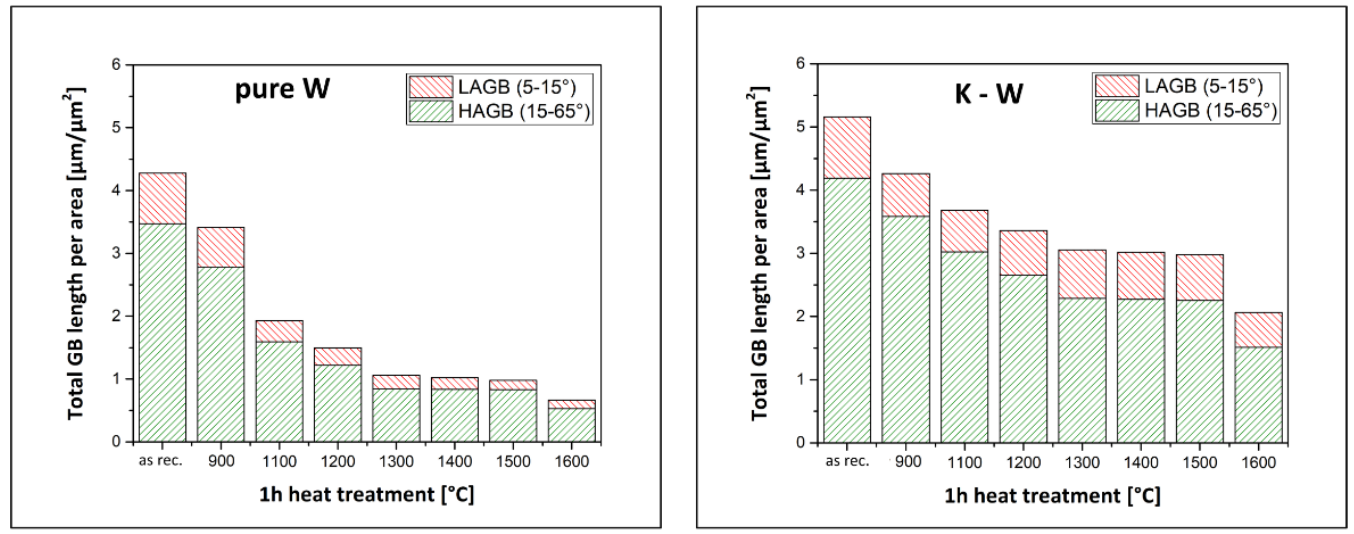

Figure 5. a) Grain boundary map of the as-received and $1600^{\circ} \mathrm{C}$ annealed pure tungsten wire, where the low-angle grain boundaries ( $L A G B, 5^{\circ}-15^{\circ}$ ) and the high-angle grain boundaries (HAGB, $\left.15^{\circ}-65^{\circ}\right)$ are identified as red and black lines, respectively. Total length of grain boundaries per scanning area of pure and potassium doped $W$ wires is given, depending on different annealing temperatures, analyzed from b) cross sectional orientation maps and c) longitudinal orientation maps. Abundance of low-angle and high-angle grain boundaries is indicated as well. 
In all the cases, the as received material shows the highest amount of GBs which consist to a large extent of high-angle boundaries. Simultaneously with initial annealing processes and increase in grain size, the length of grain boundaries reduces, with the effect being significantly pronounced for pure tungsten annealed at and above $1100^{\circ} \mathrm{C}$. At the highest annealing temperature, the total GB reduction is about $80 \%$ and $85 \%$ for the data obtained from the cross sectional and longitudinal maps, respectively. The K-doped material shows a similar trend but with a significantly smaller GB reduction which is related to the stabilization of the grain structure at elevated temperatures. A correlation can be made between different heat treatments, the nature of grain boundaries and their number fraction. The misorientations histogram shows that a fraction of LAGB is about $20 \%$ for asreceived sample. In the case of pure $\mathrm{W}$, the amount of low-angle grain boundaries increases from about 20 to about $30 \%$ after annealing at $1100^{\circ} \mathrm{C}$, which can be correlated to recovery process. With the further increase in annealing temperature, LAGB are still present, but the ratio of better ordered high-angle grain boundaries significantly increases. For heat treatments above $1300^{\circ} \mathrm{C}$, many grain boundaries are annihilated due to grain growth, many of the low-angle grain boundaries disappear and are replaced by high-angle boundaries, which is an indication of the recrystallization taking place. For a sample annealed at $1600^{\circ} \mathrm{C}$, the vast majority of grains is separated by HAGB with a fraction of over $90 \%$. K doped wire does not show such a drastic drop in the fraction of LAGB and the analyses from the longitudinal sections show a steady increase from 18.7 to $26.6 \%$ for as received and $1600^{\circ} \mathrm{C}$ respectively, indicating that the beginning of the recrystallization is shifted to higher temperatures.

\subsubsection{Evolution of the texture}

The analyses of the pole figures obtained from EBSD data confirm a strong, preferential orientation of the grains with the $<110>$ direction parallel to the wire axis, which is a direct consequence of the severe plastic deformation induced during the wire drawing process. The developed texture of both materials is very similar; therefore, to avoid repetition, only an example of the pure tungsten wire in the as received (Figure 6a) and annealed condition (Figure 6b) is depicted. All pole figures are presented using stereographic projection showing that the centre of the pole figure corresponds to the wire axis. Additionally, six peaks of lower intensity at approximately $60^{\circ}$ can be observed, forming a continuous distribution of poles along a ring. The evolution of the developed texture is not influenced by the isothermal 
annealing treatments. Even at the highest annealing temperature of $1600^{\circ} \mathrm{C}$ very little effect can be seen on the lattice orientation, as the texture remains the same with a very dominant $\langle 110\rangle$ direction. The less continuous rings are related to the increase of grain size and therefore limited grain statistics. Slight weakening of the texture after recrystallization is observed as well.

\section{a) as received}
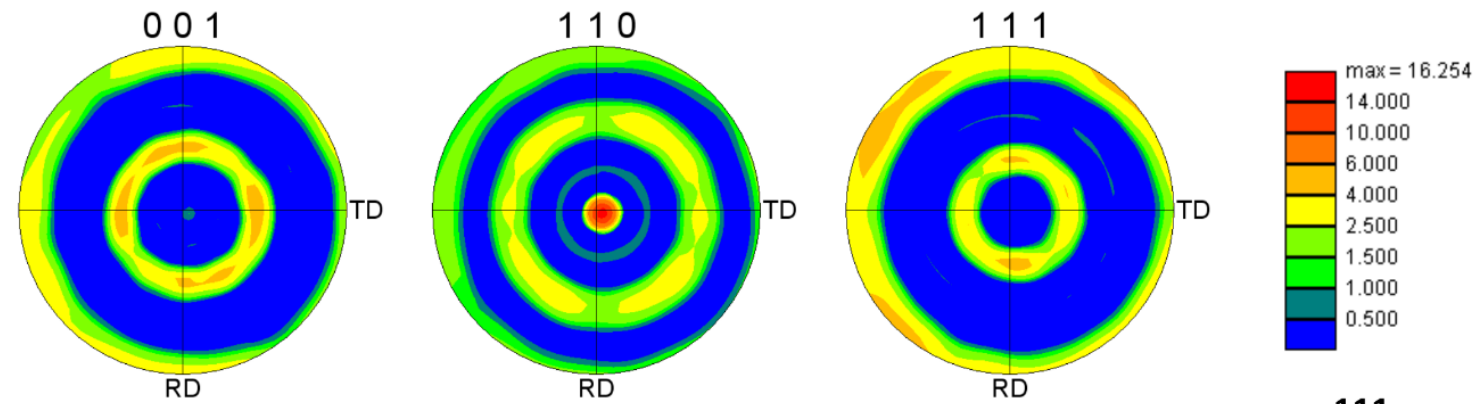

\section{b) $1600^{\circ} \mathrm{C} / 1 \mathrm{~h}$}
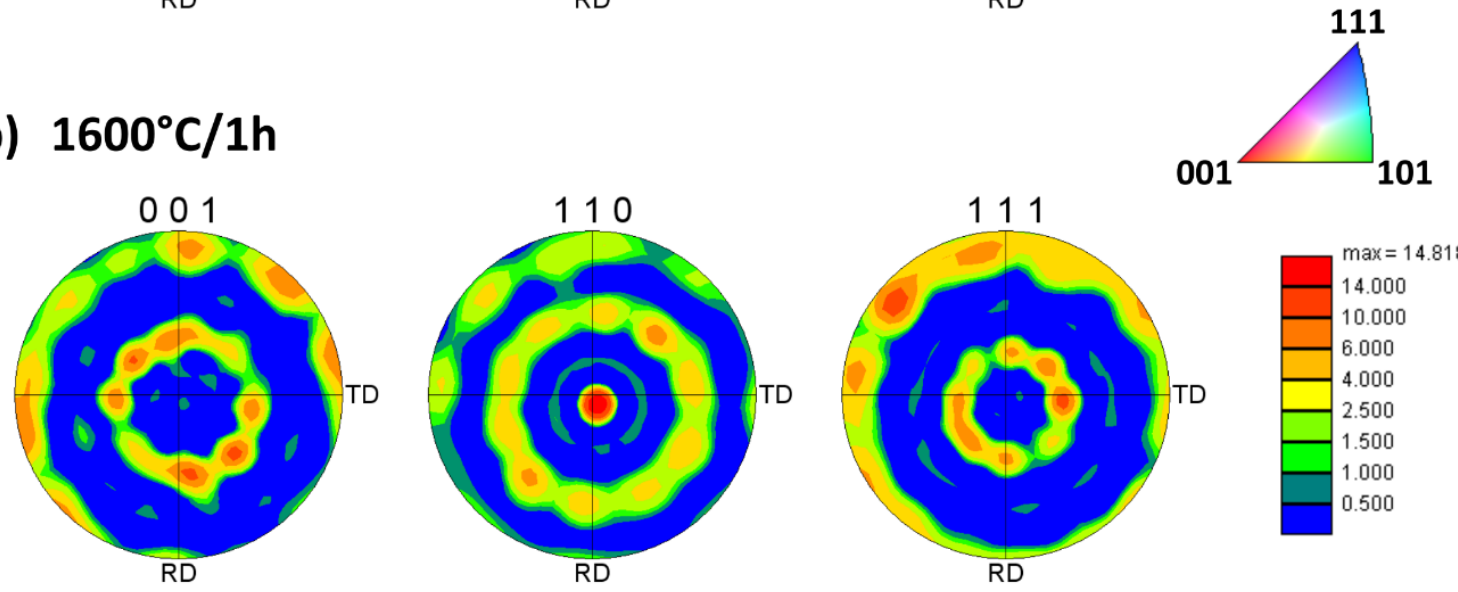

Figure 6. $\{001\},\{110\}$ and $\{111\}$ pole figures derived from EBSD texture analyses of the cross section of a pure tungsten wire in a) as received condition and b) after annealing at $1600^{\circ} \mathrm{C} / 1 \mathrm{~h}$.

\subsection{Radial microstructural investigation}

During the drawing process, a wire is imposed to a great amount of plastic deformation that is inhomogeneous throughout the cross section [16]. As a result, the heterogeneity of the stress state occurs across the diameter with a higher shear stress and strain in the surface region than in the interior of the wire. Consequently, variations of microstructural features and texture could occur, which would have a 
significant impact on mechanical properties of the materials. With that in mind, additional microstructural analyses were completed, where EBSD mapping was performed as a function of wire radius. In Figure 7, a sequence of orientation maps of the central region of the as-received pure $\mathrm{W}$ wire can be seen. The microstructural evolution across the entire diameter of the wire can be investigated by connecting the obtained scans from one edge to another.

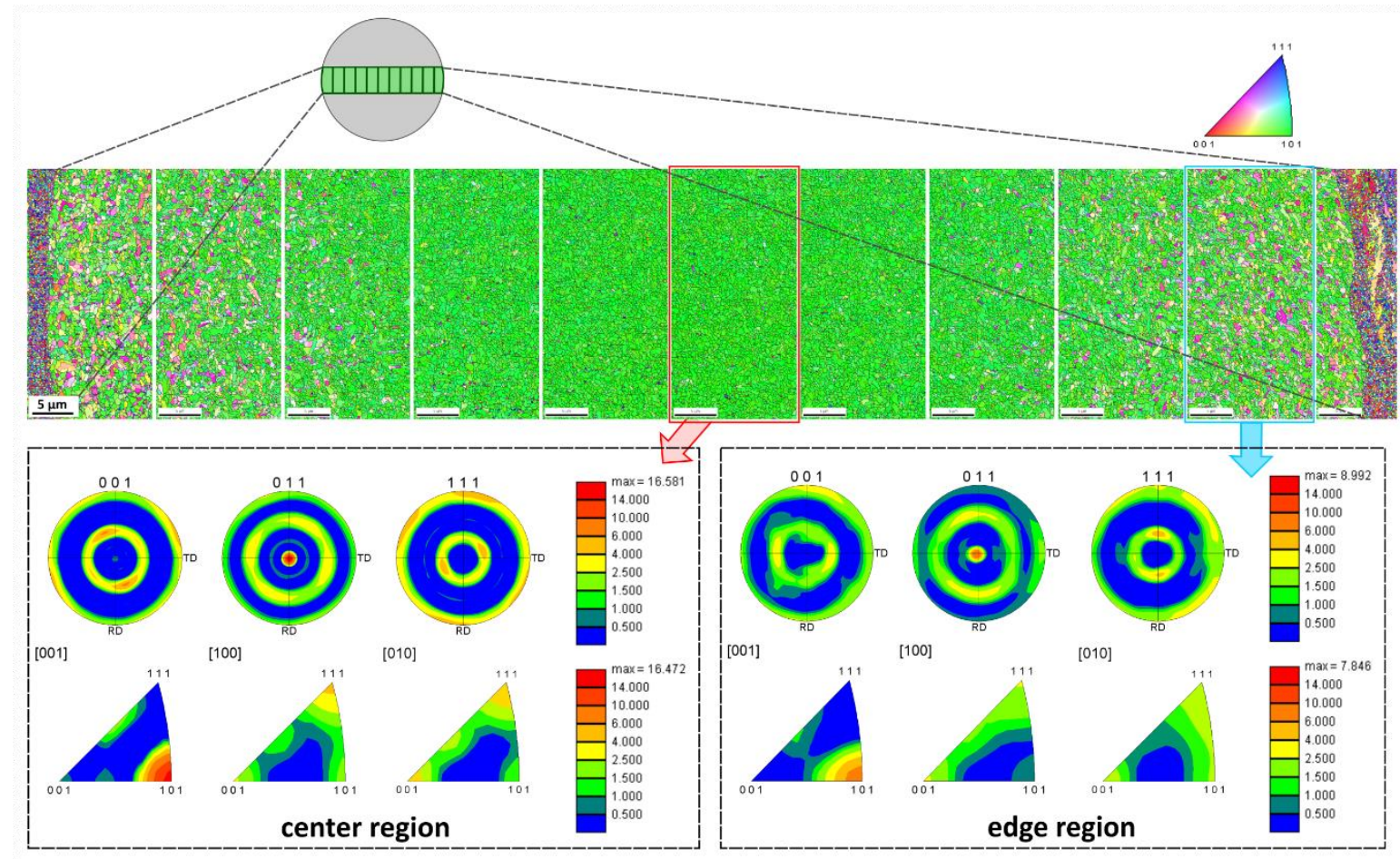

Figure 7. EBSD orientation maps of the cross section of the as-received, pure tungsten across the wire diameter. The evolution of the texture is investigated by analyses of the pole figures and inverse pole figures of the scans in central and edge region. Color coded unit triangle is given as well, representing $\langle 100\rangle$, $\langle 110\rangle$ and $\langle 111\rangle$ crystallographic directions perpendicular to the sample surface.

The qualitative analyses of the grain size do not reveal alternations throughout the cross section yielding an average area weighted grain diameter of $(0.471 \pm$ $0.005) \mu \mathrm{m}$. The grain shape, in terms of aspect ratio, is unchanged as well. However, some features of the texture in the centre and the edge region appear to be somewhat different indicating an impact of the drawing process and the resulting heterogeneity of the stress state. In the center region, a very strong $\langle 110\rangle$ fiber texture is seen with a maximum intensity in a pole figure of 16.6. Approaching the edge of the wire, a certain grain orientation change is perceived leading to the slightly 
inclined $<110>$ pole and smearing of the characteristic rings in $\{001\}$ and $\{111\}$ pole figures. Furthermore, the texture is significantly weaker with a maximum intensity of only 8.9. The variation of the maximum intensity from one edge to the other is significant and can be represented with a bell shape curve.

\subsection{Microhardness measurements}

Hardness measurements enable a fast determination of the changes of the mechanical properties in respect to different heat treatments through the correlation between the strength of the material and its grain size. Thus, the loss in hardness i.e. softening of the material occurring during annealing, complements observed alternation of the microstructure and helps identification of the different annealing stages - recovery and recrystallization. Figure $8 \mathrm{a}$ shows the results of Vickers microhardness measurements (HV0.5) as a function of the isochronal annealing temperature of the longitudinal sections for both pure and potassium doped tungsten wires. Three areas can be distinguished:

- In the as-received condition, the hardness of a pure and K-doped W wire is $683 \pm 5.8 \mathrm{HV} 0.5$ and $665 \pm 7.2 \mathrm{HV} 0.5$, respectively. After annealing for $1 \mathrm{~h}$ at $900^{\circ} \mathrm{C}$, both materials experience a moderate decrease in hardness, with the effect being more pronounced for pure $\mathrm{W}$.

- With the further increase in annealing temperature (above $1100^{\circ} \mathrm{C}$ ), a significant reduction in hardness of a pure $\mathrm{W}$ can be observed, reaching a value of $442 \pm 10.4 \mathrm{HV} 0.5$ for the sample heat treated at $1500^{\circ} \mathrm{C}$. In contrast to this, the hardness of the $\mathrm{K}-\mathrm{W}$ wire only slightly changes, changing from 615 $\pm 7.1 \mathrm{HV} 0.5$ to $564 \pm 6.2 \mathrm{HV} 0.5$.

- At the highest annealing temperature of $1600^{\circ} \mathrm{C}$, the pure $\mathrm{W}$ wire experiences a drastic drop of hardness to the lowest obtained value of $321 \pm 10.4$ HV0.5. Contrary to this strong softening, the hardness of the K-W wire remains nearly constant, indicating high temperature stability of the underlying microstructure. The lowest obtained microhardness value of this material yields $551 \pm 6.1 \mathrm{HV} 0.5$.

The observed variation of the microhardness and the stability in case of K-W wires are in excellent correlation to the evolution of the microstructure with different annealing treatments (Figures 2 and 3). In such a way, a link can be made with the grain size, which is related to the strength of the material by the well-known HallPetch relation $[30,31]$. This can be validated by plotting the hardness results of the 
samples in different annealing states against reciprocal square root of corresponding grain sizes, given as $\mathrm{d}^{-1 / 2}$ (Figure $8 b$ ). The presented exemplary plot is given for the pure $\mathrm{W}$ wire, where the dependence is shown for two values of grain size: area weighted grain diameters obtained from the cross sections (Figure 4a) and averaged vertical intercept lengths obtained from the longitudinal sections (Figure $4 b$ ). In both cases, the linear fit corresponds to the obtained results quite well and the same is also true for $\mathrm{K}-\mathrm{W}$ wire. Additionally, the linear relationship is also seen by plotting the hardness results against square root of corresponding length of grain boundaries, given as $\mathrm{d}^{1 / 2}$ (Figure 8c), with the similar behaviour observed for lengths of HAGB, LAGB and their total amount.

a)

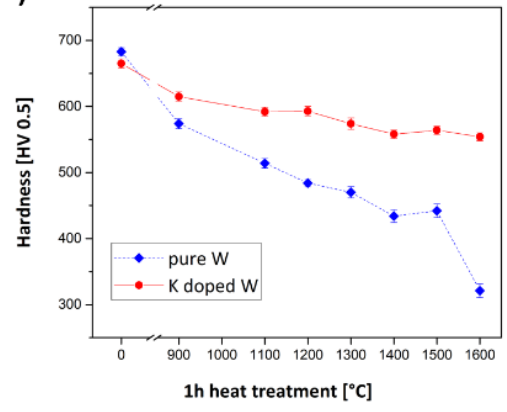

b)

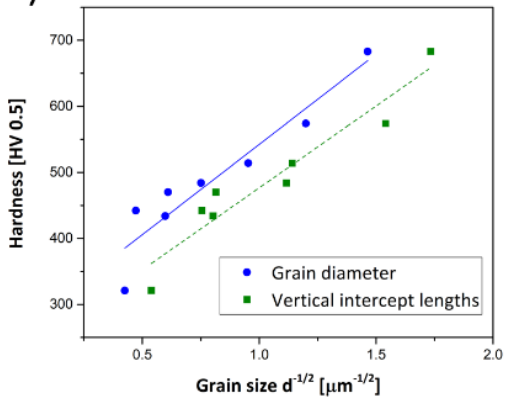

c)

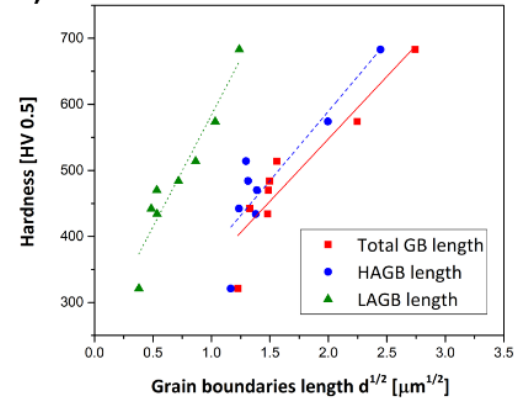

Figure 8. a) Vickers hardness (HV 0.5) results of the pure and potassium doped $W$ wires after annealing at different temperatures for $1 \mathrm{~h}$. The microhardness was measured in the longitudinal section of the sample. The relationship of the hardness data is established in respect to b) the grain size, given as $\sqrt{d^{-1 / 2}}$ and expressed in terms of grain diameters and vertical intercept lengths and $c$ ) the GB lengths, given as $\sqrt{d^{1 / 2}}$, where a comparison is made for the HAGB, LAGB and their total amount. The linear relationship is accentuated by a linear fit function.

\section{Discussion}

The main characteristics of the wire microstructure in the as received state are fibrous grains elongated along the axial direction and the development of a very pronounced $<110>$ fibre texture. Such an appearance is typically seen in heavily deformed bcc wires [32] and as expected, the results of as-received pure and $\mathrm{K}$ doped tungsten are very similar. Another peculiar feature observed in the cross section of the wire is a distinctive pattern known as grain curling or the so called Van Gogh sky structures [33]. The origin of the formation of such ribbon-shaped grains lies within the tendency of textured grains to deform by plane strain elongation [34]. 
In the course of severe plastic deformation during the drawing process, the microstructure of the wire is severely altered from the initially equiaxed grains (of the sintered ingot) to the elongated grains parallel to the axial direction and the shape change of each grain must be compatible with that of the neighbouring grains. However, with plane strain flow, this can only be accomplished by twisting of grains around each other. In such a way, grains become shaped like ribbons, curled around the wire axis establishing a very pronounced, sharp $<110\rangle$ fibre texture. As observed in our investigations, the developed $\langle 110\rangle$ texture is conserved after heat treatments, which is in a good agreement with other investigations [28]. Furthermore, the characteristic appearance of the microstructure is conserved throughout the wire diameter with a noticeable localized variation in texture in the outer region which is in a good correlation to other studies [35]. Such a heterogeneity can have a notable effect on the resulting failure mode in the edge region of the wire, as it will be shown in the second part of this contribution.

The heat treatments cause modifications in the grain structure of the wires alongside with changes of other microstructural features as well as mechanical properties. Understanding this behaviour is inevitably related to the discussion of the main three annealing phenomena: recovery, recrystallization and grain growth $[36,37]$. The recovery refers to homogeneous microstructural changes in a deformed material and occurs prior to the recrystallization; the driving force of the process is the stored energy in the deformation structure due to point and line defects. This stored energy of the material is lowered during recovery by dislocation movement through two primary thermally activated mechanisms, these being the annihilation of dislocations and the rearrangement of dislocations into lower energy configurations (polygonization and low angle grain boundaries). Both processes are achieved by glide, climb and cross-slip of dislocations leading to the overall decrease in dislocation density by the end of recovery [36].

Recrystallization in general is a thermally activated process in which new dislocation-free grains are formed within the deformed or recovered structure and grow into it; the driving force arises from the elimination of the dislocations introduced during deformation and is characterized by the movement of high-angle grain boundaries. When recrystallization sets in, dislocations are almost entirely removed from the recrystallized regions by sweeping grain boundaries. After completion of this process, further growth of the recrystallized grains may occur. The driving process of this subsequent grain growth is the reduction in stored energy of the material in the form of grain boundaries [36].

Determination of different annealing phenomena that occur in the range of investigated temperatures is inevitably linked to how one defines the recrystallization process itself, which can be quite variant in the literature. The obtained data were analysed and interpreted in regards to the respective processes as following: the 
recovery process is mostly determined through an increase in the fraction of LAGB; the recrystallization process is related to the temperature range where distinctive changes occur in the grain structure (in terms of size and shape) accompanied by pronounced softening of the material and variations in the amount and type of dominant grain boundaries; and lastly further substantial increase in grain size of the recrystallized structure is classified as grain growth.

The grain structure and related microstructural features of the two investigated materials appear rather different after annealing at successively increasing temperatures. Analysis of pure, undoped tungsten wire annealed in the range below $1100^{\circ} \mathrm{C}$ shows that the grain structure exhibited a greater degree of homogenous fine scale coarsening in the cross sections, followed by limited grain boundary migration and increased ratio of low angle grain boundaries which is all an indication of a recovery process taking place. Further proof is an initial rapid decrease of the Vickers hardness which is related to the reduction of dislocation density by dislocation rearrangement and annihilation. Annealing temperature of $1100^{\circ} \mathrm{C}$ seems to be the onset of the recrystallization as the first appearance of some isolated grains, which had grown more than neighbouring grains, is seen. Moreover, grain boundary movement is more pronounced and the total amount of boundaries is significantly reduced at this temperature. The recrystallization process seems to be complete after heat treatments up to $1400-1500^{\circ} \mathrm{C}$ as the grain boundary movement progressed to the point that the initial overall linearity of the structure in the longitudinal directions is eliminated leading to the relatively equiaxed structure of the grains. The majority of the boundaries present at this stage of recrystallization process are predominately high-angle grain boundaries. Simultaneously, a noticeable reduction of hardness is observed associated with dislocation-free, recrystallized softer regions of the material which replaced the work hardened fine fibrous microstructure. After heat treatments at the highest temperature, pure tungsten wire undergoes subsequent grain growth process where the initially fibrous microstructure is completely altered forming large, equiaxed shaped grains with an increase in average grain size by an order of magnitude. Furthermore, tremendous softening is observed with a reduction in hardness by more than $50 \%$ of initial value. The outlined results are in agreement with the previous studies of annealing properties of pure tungsten wires [38] as well as with the typically reported recrystallization temperature of tungsten $\left(1300-1500^{\circ} \mathrm{C}\right)$ [39-41]. Nevertheless, the results are not in (complete) correlation with conclusions made by Zhao [28] where it was deduced that the wire fully recrystallizes already after annealing for $3 \mathrm{~h}$ at $1000^{\circ} \mathrm{C}$. Such a conclusion was drawn mostly from the absence of the grain curling and the removal of the dislocation structures. However, a direct comparison to our findings is not straightforward as the interpretation of the different stages of annealing phenomena is not the same and is based on analyses of different 
microstructural features. Furthermore, the annealing times are not corresponding, as the wire was heat treated three times longer than in our case, which would make an additional influence to the observed microstructural changes.

In contrast to annealing properties of pure tungsten, potassium doped wire experiences significantly milder structural changes in the range of investigated temperatures. Below annealing temperature of $1400^{\circ} \mathrm{C}$ the fibrous structure is completely conserved with slight amount of lateral movement; the variation in grain size, aspect ratio and Vickers hardness are minor as well. At higher annealing temperatures, the migration of short lengths of longitudinal boundaries of all misorientations became more pronounced leading to the increase of grain width in the longitudinal direction. As more sections of grain boundaries parallel to the wire axis move in radial direction, many boundaries transverse to the drawing direction are formed. Nevertheless, an extensive grain boundary movement is successfully inhibited, while the recrystallization is shifted to even higher temperatures. The overall appearance of elongated structure is preserved with slightly lower aspect ratios of the grains and an increase in the amount of low-angle grain boundaries; this fits pretty well with the process of polygonization, which is related to the rearrangement of dislocations in the LAGB. In the case of heavily drawn doped tungsten, the process of polygonization is sometimes referred in literature as primary recrystallization or homogenous grain growth [42]. Furthermore, it can be seen that the microstructure of the doped wire after a $1600^{\circ} \mathrm{C}$ anneal was approximately equivalent to that of the undoped material annealed at $1100^{\circ} \mathrm{C}$.

It is well known that the annealing behaviour and recrystallization mechanism of $\mathrm{K}-\mathrm{W}$ wires is closely related to the presence of the dispersed second phase, namely potassium used as a dopant element [16]. The potassium is entrapped in pores during sintering of the tungsten ingot. The pores are further elongated by subsequent swaging and drawing, forming long tubes with a very high aspect ratio [43]. The areas of elongated potassium are precursors of the bubbles, which are arranged in parallel rows and all aligned in the drawing direction of the wire. Upon heating of the wire to higher temperatures, the elongated tubes divide into rows formed by individual well shaped spherical bubbles [44]. These bubble rows are the responsible mechanism for inhibiting grain boundary migration and controlling the shape and growth of the grains. The complete study of the successive annealing processes and observation of all the morphological modifications of the doped tungsten wire require performing heat treatments at significantly higher temperatures. The observed structural stabilization of the microstructure within this contribution, seems to remain an active mechanism up to $2100^{\circ} \mathrm{C}$ which is the highest annealing temperature, where the uniform, fine-grained elongated structure persists [29,45]. As the wire is heated above this temperature, secondary recrystallization or exaggerated grain growth would occur characterized by formation of large grains and predominance of 
the longitudinally oriented grain boundaries. The undoubtedly important role of potassium bubbles is seen through their pinning effect, inhibiting mostly longitudinal grain boundary motion and may hinder triple junction motion. The strings of bubbles influence the grain morphology by retarding the lateral motion of grain boundaries while grain growth occurs unimpeded parallel to the strings and to the wire axis. In such a way long grains with interlocking boundaries of large areas can be formed [46].

\section{Conclusions}

In this work, a comprehensive characterization of the pure and potassium doped tungsten wires was performed, focusing on the influence of various heat treatments on different microstructural features and mechanical properties. Annealing in the temperature range from $900-1600^{\circ} \mathrm{C}$ enabled the investigation of the microstructural stability of the two materials and arising annealing phenomena. The main findings can be summarized as following:

- The microstructure of both materials in the as-received state is very similar, consisting of fibrous grains extremely elongated along the axial direction; characteristic ribbon shaped grains curled around the wire axis can be observed in the cross sections of the both wire types.

- The grain structure of the undoped tungsten wire experiences severe modifications upon heat treatments which can be related to sequential processes of recovery, recrystallization and grain growth. A correlation can be made between the variation in grain size / shape, the nature and abundance of particular types of grain boundaries at certain annealing temperature and softening of the material, indicating that the recrystallization process is finished in the temperature range between $1300-1500^{\circ} \mathrm{C}$ for the pure material. The significant coarsening ultimately leads to the complete loss of fibrous appearance of the grains where the microstructure of the final state consists of the large, quasi-symmetric, globular $\mu \mathrm{m}$-sized grains.

- In contrast to the annealing properties of pure $\mathrm{W}$, the $\mathrm{K}$ doped wire experiences significantly milder structural changes in the range of investigated temperatures. The most pronounced changes occur above $1400^{\circ} \mathrm{C}$, where the migration of shorts lengths of longitudinal boundaries of all misorientations became more noticeable alongside with an increase in the amount of low-angle grain boundaries, indicating that the process of 
polygonization took place. Nevertheless, an extensive grain boundary movement is successfully inhibited by the dispersed second phase preserving the overall elongated microstructure, even for the highest annealing temperature.

- As a direct consequence of the drawing process, a very sharp $<110>$ fiber texture is developed by deformation induced grain rotation. The texture is slightly less prominent at the surface of the wire. Such a pronounced preferential orientation of the grains remains unaltered for both materials, even upon heat treatments at the highest annealing temperature of $1600^{\circ} \mathrm{C}$.

The main conclusion of the work is that the full recrystallization and grain growth in tungsten wire can be successfully shifted to temperatures higher than $1600^{\circ} \mathrm{C}$ by addition of potassium as a doping element. From a microstructural point of view, the application of K-doped wire for a structural parts of fusion reactors, as it is the case for $\mathrm{W}_{\mathrm{f}} \mathrm{W}$ composites, is strongly advised. The performed systematic study of the influence of heat treatments on the evolution of the grain morphology for both type of materials is crucial for the assessment of the fracture toughness of the wire. The grain size and more importantly grain shape have a tremendous influence on the micromechanisms controlling the fracture process. Deeper insights, however, will be gained from fracture tests on non-annealed, as well as annealed wires. With the help of the results presented here, it is possible to investigate the correlation of the observed microstructural features to fracture properties and embrittlement by annealing. These topics are treated in details within the second part of the contribution.

\section{Acknowledgments}

"This work has been carried out within the framework of the EUROfusion Consortium and has received funding from the Euratom research and training programme 2014-2018 under grant agreement No 633053. The views and opinions expressed herein do not necessarily reflect those of the European Commission." 


\section{$\underline{\text { References }}$}

[1] H. Zohm, Assessment of DEMO challenges in technology and physics, Fusion Eng. Des. 88 (2013) 428-433. doi:10.1016/j.fusengdes.2013.01.001.

[2] D. Stork, P. Agostini, J.L. Boutard, D. Buckthorpe, E. Diegele, S.L. Dudarev, C. English, G. Federici, M.R. Gilbert, S. Gonzalez, A. Ibarra, C. Linsmeier, A. Li Puma, G. Marbach, P.F. Morris, L.W. Packer, B. Raj, M. Rieth, M.Q. Tran, D.J. Ward, S.J. Zinkle, Developing structural, high-heat flux and plasma facing materials for a nearterm DEMO fusion power plant: The EU assessment, J. Nucl. Mater. 455 (2014) 277-291. doi:10.1016/j.jnucmat.2014.06.014.

[3] M. Rieth, S.L. Dudarev, S.M. Gonzalez De Vicente, J. Aktaa, T. Ahlgren, S. Antusch, D.E.J. Armstrong, M. Balden, N. Baluc, M.F. Barthe, W.W. Basuki, M. Battabyal, C.S. Becquart, D. Blagoeva, H. Boldyryeva, J. Brinkmann, M. Celino, L. Ciupinski, J.B. Correia, A. De Backer, C. Domain, E. Gaganidze, C. GarcíaRosales, J. Gibson, M.R. Gilbert, S. Giusepponi, B. Gludovatz, H. Greuner, K. Heinola, T. Höschen, A. Hoffmann, N. Holstein, F. Koch, W. Krauss, H. Li, S. Lindig, J. Linke, C. Linsmeier, P. López-Ruiz, H. Maier, J. Matejicek, T.P. Mishra, M. Muhammed, A. Muñoz, M. Muzyk, K. Nordlund, D. Nguyen-Manh, J. Opschoor, N. Ordás, T. Palacios, G. Pintsuk, R. Pippan, J. Reiser, J. Riesch, S.G. Roberts, L. Romaner, M. Rosiński, M. Sanchez, W. Schulmeyer, H. Traxler, A. Ureña, J.G. Van Der Laan, L. Veleva, S. Wahlberg, M. Walter, T. Weber, T. Weitkamp, S. Wurster, M.A. Yar, J.H. You, A. Zivelonghi, Recent progress in research on tungsten materials for nuclear fusion applications in Europe, J. Nucl. Mater. 432 (2013) 482500. doi:10.1016/j.jnucmat.2012.08.018.

[4] C. Linsmeier, M. Rieth, J. Aktaa, T. Chikada, A. Hoffmann, J. Hoffmann, A. Houben, H. Kurishita, X. Jin, M. Li, A. Litnovsky, S. Matsuo, A. Von Müller, V. Nikolic, T. Palacios, R. Pippan, D. Qu, J. Reiser, J. Riesch, T. Shikama, R. Stieglitz, T. Weber, S. Wurster, J.-H. You, Z. Zhou, Development of advanced high heat flux and plasma-facing materials, 92007 (2017). doi:10.1088/1741-4326/aa6f71.

[5] V. Philipps, Tungsten as material for plasma-facing components in fusion devices, J. Nucl. Mater. 415 (2011) S2-S9. doi:10.1016/j.jnucmat.2011.01.110.

[6] E. Lassner, W.-D. Schubert, Tungsten - Properties, Chemistry, Technology of the Element, Alloys and Chemical Compounds, Kluwer Academic/Plenum Publishers, New York, 1999.

[7] J. Reiser, M. Rieth, B. Dafferner, A. Hoffmann, Charpy impact properties of pure tungsten plate material in as-received and recrystallized condition $\left(1 \mathrm{~h}\right.$ at $2000{ }^{\circ} \mathrm{C}$ (2273 K)), J. Nucl. Mater. 442 (2013) S204-S207.

doi:10.1016/j.jnucmat.2012.10.037.

[8] V. Barabash, G. Federici, M. Rödig, L.L. Snead, C.H. Wu, Neutron irradiation effects on plasma facing materials, J. Nucl. Mater. 283-287 (2000) 138-146.

doi:10.1016/S0022-3115(00)00203-8. 
[9] Y. Yuan, J. Du, M. Wirtz, G.N. Luo, G.H. Lu, W. Liu, Surface damage and structure evolution of recrystallized tungsten exposed to ELM-like transient loads, Nucl.

Fusion. 56 (2016). doi:10.1088/0029-5515/56/3/036021.

[10] G. Pintsuk, S. Antusch, T. Weingaertner, M. Wirtz, Recrystallization and composition dependent thermal fatigue response of different tungsten grades, Int. J. Refract. Met. Hard Mater. 72 (2018) 97-103. doi:10.1016/j.jirmhm.2017.11.039.

[11] R. Neu, J. Riesch, A. V. Müller, M. Balden, J.W. Coenen, H. Gietl, T. Höschen, M. $\mathrm{Li}, \mathrm{S}$. Wurster, J.H. You, Tungsten fibre-reinforced composites for advanced plasma facing components, Nucl. Mater. Energy. 12 (2017) 1308-1313. doi:10.1016/j.nme.2016.10.018.

[12] B. Jasper, S. Schoenen, J. Du, T. Hoeschen, F. Koch, C. Linsmeier, R. Neu, J. Riesch, A. Terra, J.W. Coenen, Behavior of tungsten fiber-reinforced tungsten based on single fiber push-out study, Nucl. Mater. Energy. 9 (2016) 416-421. doi:10.1016/j.nme.2016.04.010.

[13] J. Riesch, M. Aumann, J.W. Coenen, H. Gietl, G. Holzner, T. Höschen, P. Huber, M. $\mathrm{Li}, \mathrm{C}$. Linsmeier, R. Neu, Chemically deposited tungsten fibre-reinforced tungsten The way to a mock-up for divertor applications, Nucl. Mater. Energy. 9 (2016) 7583. doi:10.1016/j.nme.2016.03.005.

[14] J. Riesch, T. Höschen, C. Linsmeier, S. Wurster, J.H. You, Enhanced toughness and stable crack propagation in a novel tungsten fibre-reinforced tungsten composite produced by chemical vapour infiltration, Phys. Scr. T159 (2014). doi:10.1088/0031-8949/2014/T159/014031.

[15] P. Schade, Int . Journal of Refractory Metals and Hard Materials 100 years of doped tungsten wire, RMHM. 28 (2010) 648-660. doi:10.1016/j.jirmhm.2010.05.003.

[16] E. Pink, L. Bartha, The metallurgy of doped/non-sag tungsten, Elsevier Science Publishers, 1989.

[17] B.P. Bewlay, N. Lewis, K.A. Lou, Observations on the evolution of potassium bubbles in tungsten ingots during sintering, Metall. Trans. A. 23 (1992) 121-133. doi:10.1007/BF02660859.

[18] W.D. Schubert, B. Lux, B. Zeiler, Formation and incorporation of dopant phases during technical reduction of NS-doped tungsten blue oxide, Int. J. Refract. Met. Hard Mater. 13 (1995) 119-135. doi:10.1016/0263-4368(95)00006-2.

[19] D.M. Moon, R.C. Koo, Mechanism and kinetics of bubble formation in doped tungsten, Metall. Mater. Trans. B. 2 (1971) 2115-2122. doi:10.1007/BF02917539.

[20] P. Schade, Potassium bubble growth in doped tungsten, Int. J. Refract. Met. Hard Mater. 16 (1998) 77-87. doi:10.1016/S0263-4368(98)00015-8.

[21] B.P. Bewlay, C.L. Briant, The formation and the role of potassium bubbles in NSdoped tungsten, Int. J. Refract. Met. Hard Mater. 13 (1995) 137-159.

doi:10.1016/0263-4368(94)00030-1. 
[22] O. Horacsek, L. Bartha, Development of the bubble structure from selectively deforming potassium-pores in doped tungsten wires, Int. J. Refract. Met. Hard Mater. 22 (2004) 9-15. doi:10.1016/j.jijmhm.2003.10.002.

[23] J. Riesch, J. Almanstötter, J.W. Coenen, M. Fuhr, H. Gietl, Y. Han, T. Höschen, C. Linsmeier, N. Travitzky, P. Zhao, R. Neu, Properties of drawn W wire used as high performance fibre in tungsten fibre-reinforced tungsten composite, IOP Conf. Ser. Mater. Sci. Eng. 139 (2016). doi:10.1088/1757-899X/139/1/012043.

[24] J. Riesch, A. Feichtmayer, M. Fuhr, J. Almanstötter, J.W. Coenen, H. Gietl, T. Höschen, C. Linsmeier, R. Neu, Tensile behaviour of drawn tungsten wire used in tungsten fibre-reinforced tungsten composites, Phys. Scr. T170 (2017) 7. doi:10.1088/1402-4896/aa891d.

[25] J. Riesch, J.Y. Buffiere, T. Höschen, M. Di Michiel, M. Scheel, C. Linsmeier, J.H. You, In situ synchrotron tomography estimation of toughening effect by semi-ductile fibre reinforcement in a tungsten-fibre-reinforced tungsten composite system, Acta Mater. 61 (2013) 7060-7071. doi:10.1016/j.actamat.2013.07.035.

[26] D. Terentyev, J. Riesch, S. Lebediev, A. Bakaeva, J.W. Coenen, Mechanical properties of as-fabricated and $2300^{\circ} \mathrm{C}$ annealed tungsten wire tested up to $600^{\circ} \mathrm{C}$, Int. J. Refract. Met. Hard Mater. 66 (2017) 127-134.

doi:10.1016/j.jirmhm.2017.03.011.

[27] D. Terentyev, J. Riesch, S. Lebediev, T. Khvan, A. Zinovev, M. Rasincski, A. Dubinko, J.W. Coenen, Plastic deformation of recrystallized tungsten-potassium wires Constitutive deformation law in the temperature range $22-600{ }^{\circ} \mathrm{C}$, Int. J. Refract. Met. Hard Mater. 73 (2018) 38-45.

[28] P. Zhao, J. Riesch, T. Höschen, J. Almanstötter, M. Balden, J.W. Coenen, R. Himml, W. Pantleon, U. von Toussaint, R. Neu, Microstructure, mechanical behaviour and fracture of pure tungsten wire after different heat treatments, Int. J. Refract. Met. Hard Mater. 68 (2017) 29-40. doi:10.1016/j.jirmhm.2017.06.001.

[29] J. Riesch, Y. Han, J. Almanstötter, J.W. Coenen, T. Höschen, B. Jasper, P. Zhao, C. Linsmeier, R. Neu, Development of tungsten fibre-reinforced tungsten composites towards their use in DEMO - Potassium doped tungsten wire, Phys. Scr. 2016 (2016) 14006. doi:10.1088/0031-8949/T167/1/014006.

[30] E.O. Hall, The deformation and aging of mild steel. III: Discussion of results, Proc. Phys. Soc. Lond. B. 64 (1951) 747-753.

[31] N.J. Petch, The Cleavage Strength of Polycrystals, J. Iron Steel Inst. 174 (1953) 25-28.

[32] S. Suwas, R.K. Ray, R.K.R. Satyam Suwas, Crystallographic Texture of Materials, 2014. doi:10.1007/978-1-4471-6314-5.

[33] M.R. Ripoll, J. Očenášek, Microstructure and texture evolution during the drawing of tungsten wires, Eng. Fract. Mech. 76 (2009) 1485-1499.

doi:10.1016/j.engfracmech.2009.02.012. 
[34] W.F.J. Hosford, Microstructural changes during deformation of [011] fiber textured metals, Trans. Metall. Soc. AIME. 230 (1964) 12-15.

[35] P.F. Browning, C.L. Briant, K. Rajan, B.A. Knudsen, An analysis of splitting failures during the drawing of tungsten wire, Eng. Fail. Anal. 2 (1995) 105-115. doi:10.1016/1350-6307(95)00010-N.

[36] F.J. Humphreys, M. Hatherly, Recrystallization and related annealing phenomena, Elsevier Ltd, 2004.

[37] N. Hansen, R.A. Vandermeer, Recovery, Recrystallization, and Grain Growth, Encycl. Condens. Matter Phys. (2005) 116-124. doi:http://dx.doi.org/10.1016/B0-12369401-9/00577-5.

[38] D.B. Snow, The recrystallization of commercially pure and doped tungsten wire drawn to high strain, Metall. Trans. A. 10 (1979) 815-821.

doi:10.1007/BF02658299.

[39] O. Horacsek, Properties and failure modes of incandescent tungsten filaments, IEE Proc. A (Physical Sci. Meas. Instrumentation, Manag. Educ. Rev. 127 (1980) 134141. doi:10.1049/ip-a-1.1980.0023.

[40] S.N. Mathaudhu, A.J. deRosset, K.T. Hartwig, L.J. Kecskes, Microstructures and recrystallization behavior of severely hot-deformed tungsten, Mater. Sci. Eng. A. 503 (2009) 28-31. doi:10.1016/j.msea.2008.03.051.

[41] A. Alfonso, D. Juul Jensen, G.N. Luo, W. Pantleon, Recrystallization kinetics of warm-rolled tungsten in the temperature range $1150-1350{ }^{\circ} \mathrm{C}$, J. Nucl. Mater. 455 (2014) 591-594. doi:10.1016/j.jnucmat.2014.08.037.

[42] C.L. Briant, O. Horacsek, K. Horacsek, The effect of wire history on the coarsened substructure and secondary recrystallization of doped tungsten, Metall. Trans. A. 24 (1993) 843-851. doi:10.1007/BF02656505.

[43] C.L. Briant, On the Formation of Potassium Bubbles in Tungsten Rod, 20 (1989) 179-184.

[44] C.L. Briant, Potassium bubbles in tungsten wire, Metall. Trans. A. 24 (1993) 10731084. doi:10.1007/BF02657238.

[45] D.B. Snow, The recrystallization of heavily-drawn doped tungsten wire, Metall. Trans. A. 7 (1976) 783-794. doi:10.1007/BF02644074.

[46] J.L. Walter, C.L. Briant, Tungsten wire for incandescent lamps, J. Mater. Res. 5 (1990) 2004-2022. doi:10.1557/JMR.1990.2004. 